from error in the first case, whereas in the second case $\log y$ is assumed to be normally distributed with $\log x$ free from error. If $y$ is normally distributed, the distribution of $\log y$ will not be normal, and conversely. This point has been briefly discussed elsewhere ${ }^{3}$. Presumably, Count has assumed a log normal distribution, but he has not estimated the standard errors of the parameters and consequently comparisons between their values are impossible. Furthermore, his curves have been fitted to mean values of groups; this leads to further difficulties which are not mentioned, and it would appear that mean values have been treated as if they were actually observations.

It is not clear why the particular form $\log y=\log a$ $+b \log x-c(\log x)^{2}$ should have been chosen as giving the best description of the data. A number of formulæ is listed (p. 1,034), and the author states that these are "less satisfactory". No indication of a criterion for this judgment is given, but it would appear that it was merely subjective ("It seems a very fair fit", p. 1,042). In fact, although the author prefers his formula to the allometric form, he nowhere shows that his formula does, in fact, give a closer fit: since he introduces an extra parameter, it probably does.

Count also criticizes previous workers for allowing their personal views to influence their choice of data, but he does not appear to be free from this reproach himself ; for example, he omits the Cynocephali from the Cercopithecidæ "because of their obviously high specialization" (p. 1,035). His omission of Dr. Latimer's data has been noted already.

No theoretical justification is given for the new formula and no biological interpretation of the para. meters is suggested. If it were possible to find a theoretical basis for this formula, one would find it of greater interest; but the author says that it is frankly empirical and offers no hope of any such justification. The analogy which is drawn between the cephalization exponent and the path of a projectile is quite unconvincing.

The paper is not easy to read. The author speaks of "complex exponents in place of the $b$ ": presumably he means that $b$ may be a real function of $x$ and not merely a number. The adjective 'statistical' is used where the author seems to mean 'numerical'. The sentence (p. 1,055) "This apparent fact may be important, evolutionally : for good results in geometric statistics, it is vitiating" is incomprehensible. Many other examples could be quoted.

Prof. Count has provided a valuable summary of the data relating to his subject, and his criticisms and speculations are interesting. Unfortunately, he has failed to apply modern statistical methods and to appreciate the limited value of empirical formulæ. Any such formulæ would imply that the increasing complexity of the brain, both in structure and function, which is found in vertebrate phylogeny, can be analysed in terms of its weight and that of the body of the animal. It is doubtful if this is possible since, although the physiological unit of neural activity may be the same throughout the vertebrate system, it would appear that the anatomical patterns formed by these units increase in complexity and not merely in size. For example, the optic tecta of Amphibia and Reptilia have different structural patterns, and the thalamus of Reptilia has a different pattern from that of rodents and so on. Even for these two structures the analysis must go deeper ; a fortiori it would seem that mere weight is far too superficial a unit for the analysis of the total brain.

In order to make a mathematical analysis of brain organisation, either in ontogeny or phylogeny, the physiological patterns and their correlated anatomical structures need deeper quantitative investigation. It may then be possible to form a mathematical model which will enable us not only to picture our present knowledge concisely, but also will suggest directions for future research.

DONALD SHOLI ${ }^{1}$ Count, E. W., "Brain and Body Weight in Man : Their Antecedents
in Growth and Evolution. A Study in Dynamic Somatometry",
Ann. New York Acad. Sci., 46, Art. 10, 993-1122 (1947).
${ }^{2}$ Snell, O., Arch. f. Psychiat. u. Nerv., 23 (2) (1891).

${ }^{3}$ Sholl, D., Nature, 159, 269 (1947).

\section{RUTHERFORD CELEBRATIONS IN PARIS}

$\mathrm{O}^{\mathrm{N}}$ November 7 and 8, in Paris, the World Federation of Scientific Workers, the president of which is Prof. F. Joliot-Curie, held a solemn commemoration of the tenth anniversary of the death of Lord Rutherford. This graceful and extremely successful tribute by scientific men from all parts of the world emphasized the international character of science and the deep regard and lively admiration of men from twenty nations for the work and personal qualities of the greatest of contemporary British scientists. The presence of Lady Rutherford, and of two of her grandchildren, gave a personal character to the ceremony which a purely scientific gathering would have lacked.

The conference proper began with a reception by the President of the French Republic in the afternoon of November 7 at the Elysée Palace, at which guests were received by the President and Mme. Auriol. The Premier and members of the Cabinet were present. M. Auriol spoke of the work of Rutherford and of the international character of science, and expressed optimism that the fruits of his genius and of science in general would be used for the good of mankind. Prof. F. Joliot-Curie responded. The grandeur of the Palace, the magnificence of this tribute by the French nation through its President, and the charm of our hosts, made a deep impression upon all, and especially upon the British delegates.

In the evening at 9 p.m. a solemn commemoration was held in the Great Hall of the Sorbonne. The French Foreign Minister, M. Bidault, was in the chair and the hall was crowded with more than two thousand people, including diplomatic representatives of many countries. Tributes were paid by Prof. Niels Bohr (Denmark), whose message was read by Dr. Møller, by M. de Broglie (France), Prof. M. I. Oliphant (Great Britain), Prof. Harold Urey (United States), and Prof. Joliot-Curie (president of the World Federation of Scientific Workers). A large illuminated photograph of Rutherford hung over the stage, an orchestra played before the proceedings began and between the speeches, and the recorded voice of Rutherford was heard through the loud-speaker system. This was a most solemn and moving occasion.

On the morning of November 8 further tributes were paid in the lecture theatre of the College de France by Prof. M. N. Saha (India), Sir George Thomson (Great Britain), Prof. J. S. Foster (Canada) and Mme. Irène Joliot-Curie (France). M. Louis de Broglie was in the chair. It is understood that all 
speeches will be published in French. Advantage was taken of the character of the gathering to hold a discussion on the international and social implications of modern science, a subject dominated at the present time by atomic energy, the practical fruit of the scientific labours of Rutherford and his colleagues throughout the world.

There was a reception at the Maison de la Pensée Francaise and a lecture on "The Function of International Science in the Solution of the Economic Problems of To-day" delivered in French by Prof. J. D. Bernal.

It was particularly fitting that these celebrations should have been held in France, where Becquerel and the Curies laid the foundation of nuclear physics by their pioneering discoveries in radioactivity, and especially that the daughter and son-in-law of the Curies should have been largely responsible for the conception and organisation of the conference. Those of us who were students and colleagues of Rutherford found the proceedings in every way appropriate, magnificent in conception and strangely moving. This spontaneous tribute to the genius and lovable personality of Rutherford merits the gratitude of all Britons.

The organisation of the commemoration was in the hands of a committee of the World Federation of Scientific Workers, and its great success was due largely to the generous hospitality of the French Government and its full participation in the proceedings. The United Nations Educational, Scientific and Cultural Organisation recognized the unique significance of the occasion by providing funds to cover the travelling expenses of many who attended.

M. L. OLIPHANT

\section{CULTIVATION OF THE CRICKET BAT WILLOW}

$\mathrm{I}^{\mathrm{N}}$ Forestry Commission Bulletin No. 17 (London : H.M. Stationery Office, 1946) the cultivation of the cricket bat willow is described. The tree willows are divided into two groups. In the first, the trees are pollarded and yield small produce such as stakes and poles, the latter used for hurdles and rough fencing. In the second group, timber of larger size is produced which may be used, as in some parts of the Midlands, for making field gates, but of which the best known and most important manufactured product is the cricket bat. Pollarded willows are very characteristic sights in many parts of England as, for example, in the valley of the Thames; Somersetshire marshes ; the levels of the Bedfordshire Ouse, and along many of the small streams in southern England. In most cases the agricultural population know well how to deal with this type of tree, the numbers of which do not appear to diminish in the parts of the country where they are found, and their produce furnishes a very useful source of certain types of woody material in use by the agricultural community.

When the object is to produce material of timber size, the areas devoted to willow must be treated on a more intensive forestry method, and this applies to a very high degree in the case of trees from which it is desired to obtain timber for the manufacture of cricket bats. With this object in view the willow must be selected with very great care so far as the willow stock is concerned, and to-day, for the purpose in question, it has led to an ever-increasing demand for Salix alba var. coerulea. The demand for this variety has been a matter of gradual development, and the methods of its cultivation have been carefully improved, based on trial and error with reference to methods of propagation and planting.

In the past, a number of private owners have tried to undertake the production of this high-quality willow timber, with the object of selling it as material for cricket bat production, and considerable failures have resulted. It is not that the cultivation of the willow itself is actually difficult, but a great deal of close attention is necessary, and more especially during its early life, and the right variety must be obtained at the start. It is for this reason that the Forestry Commission has had drawn up and issued this bulletin on the cultivation of this valuable product. The subject is dealt with under situation, climate, soils, propagation (by various methods), planting and tending the trees; also the various types of possible damage are discussed; the character and uses of willow timber, and finally the systematy of the cricket bat willow and its allies. In fact, the bulletin may be considered to be an up-to-date guide to any who wish to take up this interesting branch of economic tree-growing. There is also a number of plates illustrating the text.

\section{FORTHCOMING EVENTS}

(Meeting marked with an asterisk * is open to the public)

\section{Saturday, December 6}

NORTh OF ENGLAND INSTitute of Mining and Mechanical Mr. Donald Hindson, Jr. : "Some Aspects of Dutch Coal Mining".

\section{Monday, December 8}

CHEMICAL SOCIETY (in the Main Chemistry Lecture Theatre, The University, Edgbaston, Birmingham), at 4.30 p.m.-Dr. W. A. Waters : "Mechanisms of Oxidation".

INSTITUTION OF THE RUBBER INDUSTRY, MIDLAND SECTION (at the James Watt Memorial Institute, Great Charles Street, Birmingham), Black".

Tuesday, December 9

ZOOLOGICAL Societry OF LoNDON (at Regent's Park, London, N.W.8), at 5 p.m.-Scientific Papers.

Institution OF ChEMICAL ENGINEERs (at the Geological Society, Burlington House, Piccadilly, London, W.1), at 5.30 p.m.-Mr. N. H. Pratt: "The Heat Transfer in a Reaction Tank Cooled by Means of a Coil",

INSTITUTION OF ELECTRICAL ENGINEERS, RADIO SECTION (at Savoy Place, Victoria Embankment, London, W.C.2), at 5.30 p.m.-Mr. B. E. G. Mittell : "Commercial Disc Recording and Processing": Illuminating Enginenrivg Society (at the F.T.M.A. Lighting Service Bureau, 2 Savoy Hill, London, W.C.2), at

Nelson: "Decoration and Industrial Lighting" CoUnTIES SECTION (in the Material Research Laboratory, Philips Lamps, Ltd., New Road, Mitcham Junction), at 7.15 p.m.-Mr. C. G. A. Hill, assisted by colleagues: "Luminescent Materialstheir Properties and Uses", with demonstrations.

\section{Wednesday, December 10}

INSTITUTE of FUel, NORTH-WESTERN SRCMON (at the Engineers' Club, Albert Square, Manchester), at 2 p.m.-Mr. S. W. Bertenshaw : "Oil Firing Practice".

RoYAl Society of ARTs (at John Adam Street, Adelphi, London, W.C.2), at 2.30 p.m.-Mr. Michael Graham: "Science and the Fishing Industry".

Grologicat Soctetr (at Burlington House, Piccadilly, London, W.1), at 5 p.m. - Scientific Papers.

INSTITUTION OF ELECTRICAL ENGINEERS, TRANSMISSION SECTION (at Savoy Place, Victoria Embankment, London, W.C.2), at 5.30 p.m. -Mr. H. Hurworth : "Some Observations on Oil Deterioration in Transformers and Switchgear"; Mr. J. S. Forrest: "An Electrical Resistance Test for Insulating Oils"'.

MANCHESTER LITERARY AND PHILOSOPHICAL SOCIETY, SOCIAT Philosophy SkCtion (at the Portico Library, 57 Mosley Street, Man chester), at 5.30 p.m.-Lecture by Miss C. V. Wedgwood.*

Society of Chrmidat Industry, NuTrimion PANET of the Food GROUP (at the Chemical Society, Burlington House, Piccadilly, London, W.1), at 6 p.m.- "Organoleptic Tests in the Food Industry". 